\title{
Development of preschool teachers' creative potential
}

\author{
T.G. Khanova ${ }^{1 *}$, N.V. Belinova ${ }^{2}$, and N.V. Vyalova ${ }^{3}$ \\ ${ }^{1}$ Minin Nizhny Novgorod State Pedagogical University, Nizhny Novgorod, Russia \\ ${ }^{2}$ Minin Nizhny Novgorod State Pedagogical University, Nizhny Novgorod, Russia \\ ${ }^{3}$ Minin Nizhny Novgorod State Pedagogical University, Nizhny Novgorod, Russia
}

\begin{abstract}
In the structure of the teacher's professional and pedagogical competence, creativity characterizes his creative achievements and is considered as the ability to design new non-standard products and high results by activating creative abilities. The creative potential of teachers is realized in practice through the development of creative products in the field of education, and the form of implementation of such products can be very diverse - from designing and delivering a lesson to pedagogical discovery. Within the framework of this research, ways of developing the creative potential of a teacher have been studied. It is emphasized that for its development, it is necessary, first of all, the inner desire of the teacher, the actualization of the desire for self-development, and creative growth.
\end{abstract}

\section{A problem statement}

Any political changes taking place in the field of education inevitably impact the nature of the teacher's professional activity. Socio-economic transformations, modernization of the educational sphere, the latest achievements of pedagogical science and practice actualize the desire of teachers to innovate, and educational institutions that actively use innovations increase their competitiveness [1]. In a word, "innovative activity is inseparable from creativity since it provides the creating and developing of new ideas, the implementation of which results in innovation "[2].

Interest in creativity is rapidly and steadily growing today, this is due to the increasing speeding of social development, an increase in the rate of technological progress, in which more and more people are expected to be able to invent and create.

From time immemorial, the profession of a teacher has demanded from a person working with children the ability to creatively and diverse approach the process of upbringing and training. In the modern world, this requirement is growing higher, since preschool education is becoming more and more valuable and important for parents of pupils who expect from the teacher not only certain qualities, knowledge, skills, and abilities, but also a developed ability to accept the "challenge of the time", create and be responsible for creativity. In the modern world, where every day there are introduced new technologies for work with children, new regulation acts both of federal and regional level,

*Corresponding author: ipcs-profped@yandex.ru 
development centers with author's systems of training and education, the teacher simply needs to modernize or adapt own work, develop, create, transform, otherwise there is a risk of becoming unclaimed. In modern realities, this can be quite difficult, so teachers need to master such qualities as creativity. With its help, the teacher will be able to make the process of education and upbringing the most interesting, diverse, lively, and interactive. Indeed, working with children, with people in general, is not possible according to a template or instruction. It requires a constant search for solutions to problems that often arise in the process of interaction with pupils and their parents. For this, it is precisely the development of creative qualities that will allow the teacher to find an individual approach to each child.

Creativity, like any ability, can and should be developed and improved. After all, the higher the level of creative abilities, the more opportunities the teacher has in terms of designing a new, original product, as well as solving problems that arise every day in educational work with children. Creativity will not allow a teacher to become unclaimed, which means that the development of this quality is more relevant than ever in a society where the value of preschool education is increasingly emphasized.

The theoretical basis of the research was formed by the following ideas: determination of approaches to the concept of "creativity" N.A. Astashova [3], D.B. Bogoyavlenskaya [4], J. Guildford [5], H. Gavin [6], V.G. Kamenskaya [7] and others; description of the structure of creativity of G.M. Borlikova [8], E.A. Glukhovskoy [9], A.B. Zhigatova [9], V.G. Ryndak [9], F. Williams [10] and others; research in the development of creativity of teachers E. Bono [11], N.A. Stepanenko [12], Yu.A. Sergienko [13], T.V. Sunyaikina [13], and others. Thus, E. Torrens describes creativity as "the general ability of a person, which is based on the mutual disposition of intellectual qualities, personal, and also the ability to productive thinking" [10]. Studying the creative process, E. Torrens identified several stages in it: the perception of the problem, the production of ideas, the formation of a hypothesis, its verification, and finding the result.

A.G. Maslow considered creative qualities to be the natural properties of a selfactualizing person who makes full use of one's talents, abilities, and skills. He noted that every person has such a quality as creativity, but in most individuals, it fades away under the pressure of an authoritarian environment as a result of "domestication" [14].

H. Gavin understood creativity as "the property of a person to achieve effective results in non-trivial ways. He explained that "creative people not only act unusually but also always act from expedient and useful intentions" [6].

D.B. Bogoyavlenskaya understands creative qualities as such personality traits, thanks to which a person can come up with an original, creative approach to solving a problem. D.B. Bogoyavlenskaya is convinced that creativity is identical to art, because these two processes are called upon to create, generate new, non-standard, original, and unique [4]. N.A. Astashova argues that "the teacher's creativity is a distinctive feature of the teaching profession, the development of which provides, on the one hand, objective (social, material, personal) prerequisites, conditions for creativity, and on the other hand, the development of a set of key abilities for creative self-realization of the individual" [3]. When we consider creativity in the system of professional competence, we are talking first of all about those creative successes of the teacher, in which he/she presents his creative skills in creating new, unusual, original professional products. When evaluating this product, we look at its uniqueness, novelty, the value of decisions made, an original way of organizing activities that minimizes energy costs.

A creative teacher treats innovation not as an integration of ready-made methods for solving pedagogical problems, but as a transformation, improvement, and invention of a new way based on their interests and preferences of students. The content of creativity includes knowledge about possible ways to find new ways and solutions, readiness to learn 
new things, and the need to design them. Understanding the creative component of the teacher's innovative activity is based on the analysis of the phenomenon of creativity, which determines the creative nature of the teacher's activity, which is found at a certain stage of the innovation process [13]. In other words, all types of pedagogical creativity associated with a radical change in the content of the professional activity, the conditions and methods of its implementation, are classified as creative manifestations.

Creative qualities are the qualities necessary for a teacher in his activities. From the analysis of the above definitions, we see that creativity allows a person to act extraordinarily in a non-standard situation, to react quickly, and solve problems using a variety of original approaches. And if we look at the work of a teacher, we will see that the entire pedagogical process consists of a series of various extraordinary problems and tasks that require creative resolution, interaction with pupils just requires teachers to find an individual approach that is necessary for each specific child. And to pick that "cherished key", creativity is needed, like the ability to find, invent, create something that will help solve any problem.

V.A. Kan-Kalik rightly argued that if the teacher ceases to be interested in the tasks of transformation, and only the informational and "event" side of the matter comes to the fore, then his work ceases to be creative, and, therefore, the pedagogical process fails [4], therefore, creativity is not just an important quality of a teacher, it is a professional necessity for effective and efficient work.

Many researchers, both domestic and foreign, have been studying the concept and structure of creativity. For example, F. Williams, based on the ideas of J. Guildford and E. Torrance, designed his model of the structure of creativity [15]. The proposed model includes two groups of factors: cognitive-intellectual and personality-individual. The cognitive-intellectual should include flexibility, fluency, sophistication, and originality of thinking.

Personal and individual include:

- ability to take risks, the anticipation of possible failures, criticism in their address;

- the ability to search for alternative solutions, the ability to navigate complex issues;

- cognitive activity, developing intuition, readiness to find a way out in difficult situations;

- developed imagination, the ability to go beyond reality, to fantasy, etc. [15].

This approach to determining the structure of creativity brings opportunities for a holistic reflection of the entire set of its various manifestations [10]. According to G.M. Borlikova, the ability of a person to think divergently can also be attributed to the components of creativity. Data on the lack of connection between intelligence and the effectiveness of problem-solving prompted scientists to identify this type of thinking. Indeed, the productivity of solving problem situations is due to the ability to quickly process the available information [8].

The creative potential of a teacher is an integrative education of a personality that combines knowledge and skills, personal abilities, beliefs, and attitudes, and serves as the basis for effective creative professional activity. Creative potential is part of the creative, it is a narrower concept characterized by a higher level of optimization of the ratio of goals, objectives, means.

The structure of the teacher's creative potential is presented in the works of E.A. Glukhovskoy, V.G. Ryndak, A.B. Zhigatov as a combination of several components [9]:

- motivational component (positive attitude and desire for creative activity;

- content component (depth and awareness of knowledge, the ability to apply them in new non-standard situations); 
- an operational component (a high level of formation of skills and abilities necessary for fruitful activity, mastering the methods and techniques of creative educational and cognitive activity) [9].

\subsection{The objective of the work}

The purpose of this study is a theoretical and experimental study of the ways and means of developing teachers' creativity.

The goal is achieved by solving some relevant tasks:

1. Analyze the theoretical foundations of the problem of developing teachers' creativity;

2. Research the level of creativity development of the study's participants;

3. Design and introduce a system of activities aimed at developing the creativity of teachers;

4. Measure and analyze the efficiency of the study.

The study is based on the use of a complex of research methods: analysis of psychological and pedagogical literature, pedagogical experiment, conversation, testing, mathematical processing of the data obtained, comparative analysis of the results.

The research was carried out based on preschool institutions in the city of Nizhny Novgorod, Russia. The participants' pool comprised of 20 teachers.

The experimental study was carried out in three stages.

The first stage, the diagnostic experiment, was aimed at determining the level of creativity development of preschool teachers.

The second stage is a formation experiment, the goal of which was to develop and test a system of events, projects, activities for the development of creativity, including interactive methods.

At the third stage of the control experiment, the following tasks were solved:

1) to measure and analyze the level of development of teachers' creativity;

2) compare the results of the diagnostic and control experiments, define the degree of work efficiency.

To carry out the diagnostic stage of the experiment, the following diagnostic tools were selected:

- test of verbal creativity by S. Mednik (an adaptation of A.N. Voronin, adult version) [16];

- test of non-verbal creativity (E. Torrance's method, adapted by A.N. Voronin) [16];

- test for the definition of divergent (non-standard) thinking by H. Sievert [16].

\section{Materials and the results of the research}

Analysis of the results of S. Mednik's test showed that $40 \%$ of teachers have a low level of development of verbal creativity in the experimental group, in the control group - $30 \%$, these subjects picked up the fewest original answers to the proposed task, they often found it difficult to answer; the average level of verbal creativity in the EG(experimental group) is possessed by $40 \%$ of teachers, in the CG (control group) - 50\%, these subjects did not have any difficulties with the task, but their answers were not original enough; $20 \%$ of teachers of both groups have a high level of development of verbal creativity, the subjects gave original answers, the task was completed quickly, without difficulty.

Analysis of the results of the test of non-verbal creativity by E. Torrens showed that $40 \%$ of teachers in the experimental and control groups have a low level of non-verbal creativity, their drawings were not original; $30 \%$ of teachers have an average level in the $\mathrm{EG}, 50 \%$ in the $\mathrm{CG}$, the number of original drawings of these subjects was not enough; 
$30 \%$ of teachers have a high level in the EG, $10 \%$ in the CG, most of the subjects' drawings were original.

According to the results of the analysis of the performance of the test by H. Sievert, it was found that $30 \%$ of teachers have a low level of development of thinking creativity in the EG and CG, it was quite difficult for these subjects to cope with the task, they could not give the required number of answers; $50 \%$ of teachers have an average level in the EG, in the CG $-40 \%$, while performing the task the subjects had slight difficulties, in this regard, the number of original answers was not enough; $10 \%$ have a high level in the EG, in the CG - 30\%, the subjects gave a sufficient number of original answers, quickly, without difficulty.

After analyzing the results of all diagnostic methods, we concluded that the creativity of teachers is not sufficiently developed, the percentage of educators with a low level of development of creative qualities is high, and there are very few teachers with high indicators. Most teachers have an average level of creativity development, but we believe that this is not enough for effective work with children, therefore, further work with the teachers of the experimental group on the development of creativity was determined.

Upon completion of the formation experiment, a competitive quiz was held, which included several creative tasks, which allowed teachers to independently track the development of their creativity, the ability to solve problems outside the box.

Based on the results of the analysis of the results of the control experiment, we found that the number of teachers with a high level of development of creative qualities in the experimental group increased significantly (from $20 \%$ to $50 \%$ ), the number of teachers with an average level of creativity increased by $10 \%$, the low level was reduced to zero. There were minor changes in the control group.

The analyzed components allow us to highlight the characteristics of the personality of a teacher with a high level of creative potential:

- a positive attitude towards profession;

- longing for developing professional, creative personal qualities;

- longing for developing achieving professional mastery;

- constant self-development;

- awareness of the theoretical foundations of their professional activities, which includes a creative component;

- regular self-education and professional development;

- the ability to plan and organize their professional activities, to select effective means for the organization; produce reflection and self-assessment; adjust activities based on the analysis;

- the ability to foresee the educational result, possible problems;

- the ability to generate non-standard ideas to develop them in detail; the ability to apply a variety of strategies, techniques, tools in solving problem situations.

Table 1. Criteria for assessing the level of development of the creative potential of a teacher [12].

\begin{tabular}{|c|c|c|}
\hline High level & Medium level & Low level \\
\hline \multicolumn{3}{|c|}{ The creative orientation of the teacher } \\
\hline $\begin{array}{l}\text { High level of motivation for } \\
\text { success. Readiness for } \\
\text { continuous growth and } \\
\text { development. The need for } \\
\text { self-expression. Has a high } \\
\text { interest in increasing the level } \\
\text { of creativity development. }\end{array}$ & $\begin{array}{l}\text { Unstable level of success } \\
\text { motivation. Unconscious } \\
\text { readiness for growth and } \\
\text { development. Partial need for } \\
\text { self-expression. Interest in } \\
\text { increasing the level of } \\
\text { creativity development is } \\
\text { unstable. }\end{array}$ & $\begin{array}{l}\text { There is no motivation for } \\
\text { success. } \\
\text { There is no readiness for } \\
\text { growth and development, as } \\
\text { well as for self-expression and } \\
\text { increasing the level of } \\
\text { creativity. }\end{array}$ \\
\hline
\end{tabular}




\begin{tabular}{|c|c|c|}
\hline High level & Medium level & Low level \\
\hline \multicolumn{3}{|l|}{ Creative literacy of a teacher } \\
\hline $\begin{array}{l}\text { Knows what creativity and } \\
\text { creativity are. Knows the } \\
\text { content and structure of the } \\
\text { above potential. Knows all the } \\
\text { latest technologies for the } \\
\text { development of creative } \\
\text { qualities and diagnostic } \\
\text { techniques to the smallest } \\
\text { detail. }\end{array}$ & $\begin{array}{l}\text { Knowledge about the essence } \\
\text { of concepts is available, but } \\
\text { not fully. There is awareness } \\
\text { of some of the technologies } \\
\text { and diagnostic methods for } \\
\text { studying creative potential. }\end{array}$ & $\begin{array}{l}\text { The concepts are not learned. } \\
\text { There is a lack of knowledge } \\
\text { about the structure and content } \\
\text { of creative potential. There is } \\
\text { no awareness of the } \\
\text { technologies for working on } \\
\text { the development of creative } \\
\text { potential. There is also no } \\
\text { diagnostic method. }\end{array}$ \\
\hline \multicolumn{3}{|l|}{ Creative skills of the teacher } \\
\hline $\begin{array}{l}\text { Can independently design } \\
\text { pedagogical activity, focuses } \\
\text { on general and integrative } \\
\text { creative knowledge. } \\
\text { Knows how to independently } \\
\text { organize pedagogical } \\
\text { activities. Can independently } \\
\text { carry out introspection and } \\
\text { self-assessment. } \\
\text { Knows how to independently } \\
\text { correct pedagogical activities } \\
\text { based on self-esteem. }\end{array}$ & $\begin{array}{l}\text { Not always able to } \\
\text { independently perform all } \\
\text { those actions that correspond } \\
\text { to a high level of } \\
\text { development. often asks for } \\
\text { help. }\end{array}$ & $\begin{array}{l}\text { It is difficult to plan, organize, } \\
\text { analyze, correct their } \\
\text { pedagogical activity, produce } \\
\text { reflection, and self-assessment. } \\
\text { Not able to foresee the planned } \\
\text { result. } \\
\text { Not able to develop a large } \\
\text { number of ideas, including } \\
\text { non-standard ones, to use a } \\
\text { variety of possible ways to } \\
\text { solve problems. }\end{array}$ \\
\hline
\end{tabular}

The formation and development of the teacher's creative potential are facilitated by:

- manifestation and development of subjectivity, initiative, freedom, and independence of choice;

- reflection and introspection of the dynamics of their own professional and personal growth;

- the ability to pedagogical modeling "as an element and construct of the formation of the productivity and success of the individual" [17, p. 1];

- design and implementation of the educational process, taking into account professional and personal values and motives [18].

The analysis of the literature showed that creativity in the pedagogical process is a necessary quality of the educator. A teacher, whose creative abilities are at the proper level of development, easily organizes the process of teaching and upbringing in a creative, extraordinary, non-standard way. And a non-trivial approach in the activities of the educator allows us to take a fresh look at the problem and achieve the best results of its solution, which means that it allows to largely optimize the process of children's development in preschool education institutions. In this regard, the problem of finding optimal ways to develop professional competence in general, and the development of creativity, in particular, is actualized.

Creativity cannot be taught, you cannot show and tell how it is to be a creative person, it must be developed in oneself within the framework of continuous professional growth and development, first of all, for self-identification and self-realization [19]. The origins of the teacher's creativity are formed from the student's bench as a result of performing a variety of practice-oriented and creative tasks [20]. The development of the creative potential of an individual within the framework of professional training of a teacher is due to the orientation of students' activities towards creativity, the realization of the subjective possibility of self-realization by creating a qualitatively new, original product $[21,22]$.

The development of creative abilities, as a structural component of professional competence, is possible through the creation of a continuous education system designed to ensure constant professional self-improvement of teachers through the implementation of 
professional educational programs [23], including a system of special exercises and games of an interactive nature. Such methods can help teachers reveal their capabilities, clearly show what needs to be done to become a creative person. Moreover, interactive methods do not carry a heavy mental burden, like traditional ones, for example, lectures, seminars, etc. On the contrary, they allow us to relax, switch from the main activity, they usually take place in a relaxed atmosphere, in a playful way, which in turn will help teachers absorb the necessary information without much effort and tension.

We began a formation experiment on the development of teachers' creativity with an intellectual game of a competitive nature, in the process of which the teachers performed certain tasks, evaluated by points. This lesson showed the teachers how developed their creative qualities are, whether they can solve non-standard problems. In addition to intellectual games, we organized and conducted a business game, not quite ordinary, but metaphorical. This type of game not only contributes to the development of creative abilities but also helps to develop the largest number of ideas for the proposed problem. A metaphor is taken as the basis for the plot of a business game, it can be a fairy tale, legend, myth, etc., containing a problem similar to the real one. So, as a real problem, we took the following: "How to attract parents to our kindergarten?" After listening to the views of teachers on this issue, we recalled the famous Russian folk tale "The Frog Princess" and drew an analogy between our problem and the problem of the frog. As Ivan Tsarevich cannot see the beautiful Princess in the frog, so the parents do not see in an institution unknown to them all its best qualities and guarantees of the successful upbringing of their child. The teams of the participants brought their ideas to life with the help of creative tools - flipchart paper, clippings from magazines, felt-tip pens, colored pencils, and at the end presented their work to each other. Gradually, we moved from the fairytale situation of the game to a real problem, made parallels, translated the language of metaphor into the language of reality. Thus, teachers get a real understanding of a possible non-standard solution to the problem. The metaphor activates the creative abilities of the participants in the game, removing the usual stereotypes, switches attention from the statement of the problem to possible ways of solving it.

During the formation stage of the experiment, we used mainly interactive methods of technology: brainstorming, training, master class, and quest. In the process of completing the quest, teachers were able to truly get away from the work process, go deep into childhood, transform from educators into researchers participating in the search for a mysterious chest, solving fascinating puzzles and riddles. The brainwriting method allowed teachers to learn to find something new, non-standard in ordinary things. In the process of a lesson on the topic "Optional education in kindergarten", teachers did not just generate ideas, but modified them, changed them, which required them to use their creative thinking and imagination. Reverse brainstorming allowed educators to look at a proposed problem from a different angle. From the development of creativity, this is very useful, since looking at ordinary things from a different angle, contributes to the development of non-standard thinking. Thus, the development of creativity took place in an interesting and exciting form, teachers were able not only to increase the level of their creative abilities but also to learn productive interaction and co-creation. The final activity was the development of the project by the teachers - the creation of the author's summary of the lesson. The key point in the development of this synopsis was precisely his authorship, as well as the novelty and originality. A project is a technology in which learners collect information on their own. The project completed a series of events that we conducted; in the process of its creation, the teachers independently developed their creativity:

- using new, previously not applied techniques in work with children;

- creating manuals, games, crafts for classes with their own hands;

- coming up with your riddles, surprise moments, poems, stories, fairy tales, quests; 
- providing children with non-engaging material in an interesting, creative way;

- creating an outline, making the best of imagination and creativity.

\section{Conclusions}

The data obtained testify to the effectiveness of the study aimed at developing the creative qualities of teachers. It has been proven that creativity, like any ability, can and should be developed and improved. The higher the level of creative abilities, the more opportunities a teacher has to find a non-standard, most optimal way to solve problems arising in the pedagogical activity. Creativity, therefore, makes it possible to act outside the box, to quickly make the necessary decision, using original approaches.

The development of the creative potential of teachers is especially important today due to the action of several factors: the blurring of the spiritual and moral ideals prevailing in society, the stereotyped thinking of teachers, standardization of educational approaches, focus on social order, etc. On the other hand, focus on the huge potential of the preschool period of childhood, curiosity and high emotional susceptibility of children to external influences and the need for individualization of education reinforce the value and significance of preschool education, where a competent and professionally oriented teacher has been and remains a key figure.

\section{References}

1. N.N. Tuzova, Young scientist, 25, 316-319, access mode: https://moluch.ru/archive/159/44865/ (2019)

2. D.D. Yarkova, T.G. Mukhina, V.A. Malinin, S.N. Sorokoumova, Vestnik of Minin University, 8, 2 (31), 14 (2020)

3. N.A. Astashova, Teacher: the problem of choice and the formation of values, p. 272 (Moscow-Voronezh: "MODEK", 2000)

4. D.B. Bogoyavlenskaya, Psychology of creative abilities, p. 320 (Moscow: "Academy", 2002)

5. J. Guildford, Three sides of intellect, p. 456 (Moscow: Progress, 1965)

6. H. Gavin, Cognitive psychology, p. 272 (Saint Petersburg: Publishing house: Peter, 2003)

7. V.G. Kamenskaya, I.E. Melnikova, Psychology of development: general and special issues, p. 368 (Saint Petersburg: Publishing house: Childhood-press, 2008)

8. G.M. Borlikov, Formation of creativity of the future teacher of technology in the process of vocational education, p. 99 (Elista: Kalm Publishing House University, 2012)

9. M.M. Kashapova, T.G. Kiseleva, T.V. Ogorodova, Creativity as a key competence of a teacher, p. 392 (Yaroslavl: IPK "Indigo", (Eds.), 2013)

10. E.P. Ilyin, Psychology of creativity, creativity, giftedness, p. 448 (Saint Petersburg: Publishing house: Peter, 2012)

11. E. Bono, Lateral thinking. Textbook of creative thinking, p. 384 (Moscow: Publishing house: Potpourri, 2018)

12. N.A. Stepanenko, The technology of development of the creative potential of the future teacher in creative educational and professional activity, p. 156 (Moscow: FLINT, 2020) 
13. Yu.A. Sergienko, T.V. Sunyaikina, Scientific and methodological electronic journal Concept, S3, 81-85 (2016)

14. T.S. Panina, L.N. Vavilova, Modern ways of enhancing learning, p. 176 (Moscow: Academy, 2008)

15. E.V. Getmanskaya, Bulletin of the Moscow State University for the Humanities M.A. Sholokhov. Pedagogy and psychology, 1, 25-33 (2010)

16. E.E. Tunik, Modified creative tests of Williams, p. 97 (Saint Petersburg: Publishing house: Rech, 2003)

17. O.A. Kozyreva, Vestnik of Minin University, 8, 2 (31), 1 (2020)

18. T.F. Bashina, Young scientist, 4, 521-525, access mode: https://moluch.ru/archive/51/6639/ (2013)

19. I.Y. Burkhanova, G.L. Drandrov, S.S. Ivanova, A.V. Stafeeva, N.B. Vorobyov, V.A. Balchugov, E.V. Ignatyeva, International journal of applied exercise physiology, 9, 4, 117-124 (2020)

20. L.I. Ilyashenko, O.I. Vaganova, Z.V. Smirnova, N.V. Bystrova, S.N. Kaznacheeva, Amazonia investiga, 8, 22, 701-710 (2019)

21. I.V. Shovgurova, MNCO, 6, access mode: http://cyberleninka.ru/article/n/k-voprosuo-formirovanii-tvorcheskogo-potentsiala-buduschego-uchitelya-tehnologii-vprotsesse-professionalnoy-podgotovki (2009)

22. O.I. Vaganova, A.V. Lapshova, M.M. Kutepov, S.N. Tatarnitseva, E.V. Vezetiu, Amazonia investiga, 9, 369-375 (2020)

23. T.G. Khanova, N.V. Belinova, Problems of modern pedagogical education, 67-3, 240$243(2020)$ 